\title{
A Novel Design of Parasitically Gap Coupled Patches Forming an Elliptical Patch Antenna for Broadband Performance
}

\author{
Vijay Sharma \\ Department of Physics, Government Mahila Engineering College, Ajmer 305002, India \\ Correspondence should be addressed to Vijay Sharma; phyvijay@gmail.com
}

Received 21 January 2014; Accepted 6 June 2014; Published 1 July 2014

Academic Editor: Samuel Ver Hoeye

Copyright (C) 2014 Vijay Sharma. This is an open access article distributed under the Creative Commons Attribution License, which permits unrestricted use, distribution, and reproduction in any medium, provided the original work is properly cited.

\begin{abstract}
A novel single layer assembly of gap coupled elements in elliptical shape is proposed in this communication to achieve broadband performance. Among the five patches considered in the present assembly, two pairs of patches having different patch areas are arranged around an edge truncated elliptical patch. The central edge truncated elliptical patch is fed through an inset feed arrangement and the other patches are parasitically gap coupled to the central patch. With such an arrangement, an enhanced impedance bandwidth of $2.45 \mathrm{GHz}$ (or $36.2 \%$ ) with respect to central frequency $6.1 \mathrm{GHz}$ is achieved. Three resonant modes are excited with this arrangement giving improved bandwidth and gain in comparison to a conventional elliptical patch antenna. The simulated radiation patterns of proposed arrangement of patches suggest that these are identical in shape and direction of maximum radiations is directed normally to assembly of patches.
\end{abstract}

\section{Introduction}

With an escalating demand of mobile communication systems and emergence of modern wireless communication systems, need of broadband planar antennas to cover a wide frequency range is realized. The design of a proficient wide band compact size antenna, for modern communication systems, is a major challenge. Extensive work on microstrip patch antennas has been done owing to their advantages such as being of low-profile, conformability, low-cost fabrication, and ease of integration with feed networks [1,2]. Conversely, conventional microstrip patch antennas have very narrow impedance bandwidth (1-2\%) which poses a design challenge for the microstrip antenna designer to meet the broadband requirements. There are numerous and well-known methods to increase the bandwidth of antennas, including increase of the substrate thickness, use of low permittivity substrate material, use of appropriate impedance matching and feeding techniques, use of multiple resonators, and the use of slotted antenna geometry. However, bandwidth and size of an antenna are in general mutually conflicting properties; that is, an improvement of one of these characteristics normally results in degradation of the other [3-6].
In recent time, several techniques have been anticipated to enhance the bandwidth of a microstrip antenna. Yang et al. [7] demonstrated the performance of a single layer wideband rectangular patch antenna with achievable impedance bandwidth greater than $20 \%$. Abdelaziz [8] proposed a microstrip antenna with two different radiating elements connected together through a matched section which is embedded on a single layer structure to give wide bandwidth. Another technique involves multilayer structures with parasitic patches like E, V, and $\mathrm{H}$ shapes, which excites multiple resonant modes [9]. V. Sharma M. M. Sharma [10] presented a wideband gap coupled assembly of rectangular microstrip patches applicable in lower band and upper band of Wi-Max applications utilizing six directly and parasitically coupled patches. The proposed antenna works in the lower band $(2.4-2.69 \mathrm{GHz})$ and upper band $(5.25-5.85 \mathrm{GHz})$ of Wi-Max systems. Singh et al. [11] presented the analysis of dual band L-strip proximity fed gap coupled compact semicircular disk patch antenna using circuit theory concept and found that antenna resonates at two distinct modes, that is, $1.3 \mathrm{GHz}$ (with impedance bandwidth $6.61 \%$ ) and $6.13 \mathrm{GHz}$ (with impedance bandwidth 6.02\%) for lower and upper resonance frequencies, respectively. Kumar and Singh 


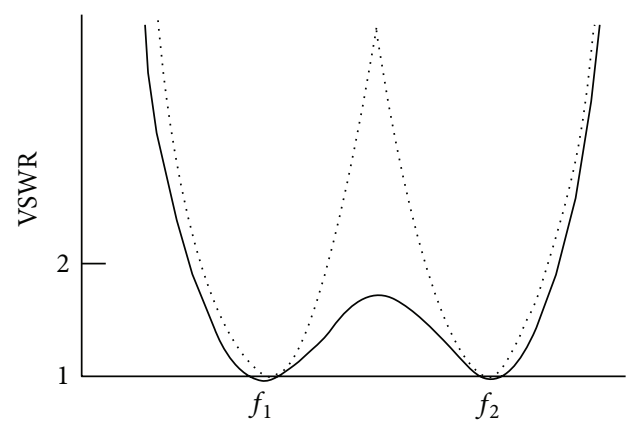

(a)

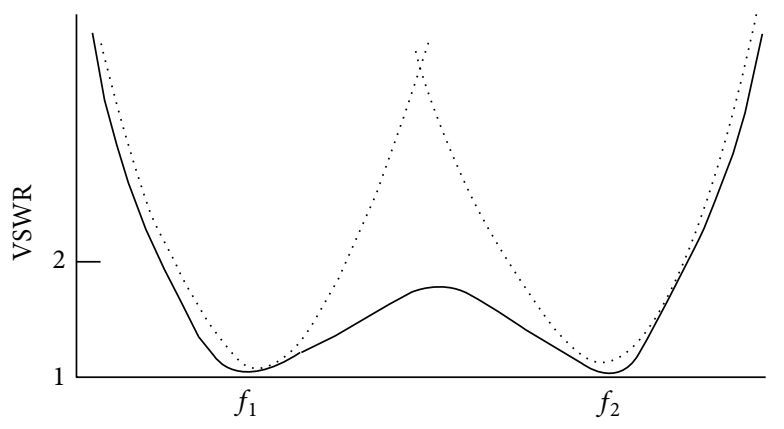

(b)

FIGURE 1: VSWR plot of two coupled resonators having (a) narrow and (b) wide bandwidth (...) individual resonators and (-) overall response.

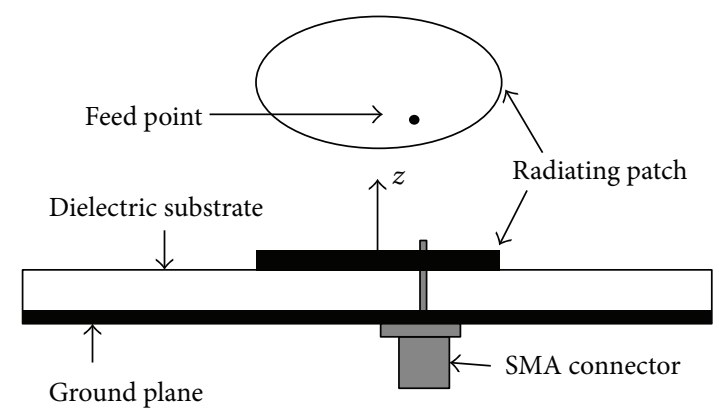

(a)

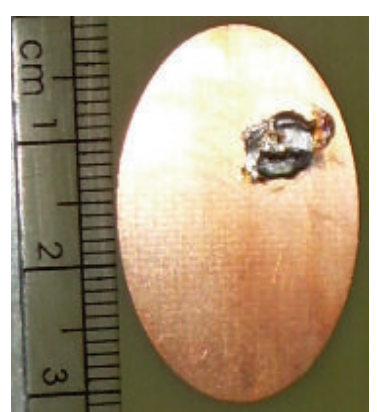

(b)

FIGURE 2: (a) Side view of EMPA structure with feed arrangement. (b) Geometry of designed elliptical patch antenna.

[12] presented a technical review on gap coupled microstrip antennas and concluded that the gap coupled microstrip antennas give a large bandwidth as compared to the conventional microstrip antennas. In this review challenges with gap coupled microstrip antennas and types of gap coupled microstrip antennas as well as numerical methods of calculating various parameters of the gap coupled microstrip antennas are discussed. The coplanar arrangement with one or more parasitic patches to attain broadband operation has also been reported in several papers in the literature [1316]. Under these arrangements, tight coupling requires small gaps between elements, which can cause fabrication and operational problems, but larger bandwidths up to $25 \%$ can be achieved.

Among the conventional patch geometries, microstrip antennas with rectangular, circular, or triangular shapes are widely analyzed. Other regular shapes of patch geometries are rarely touched upon perhaps due to involvement of difficult mathematical modeling and involved boundary conditions in their analysis. For example, elliptical patch geometry cannot become popular perhaps due to involvement of elliptical coordinate systems and application of Mathieu's function in association with involved boundary conditions during theoretical analysis $[17,18]$. However, owing to the advantage of having smaller patch size at a given frequency, as compared to rectangular and circular patch antennas, several papers on elliptical patch antennas may be seen in recent times [19-21].

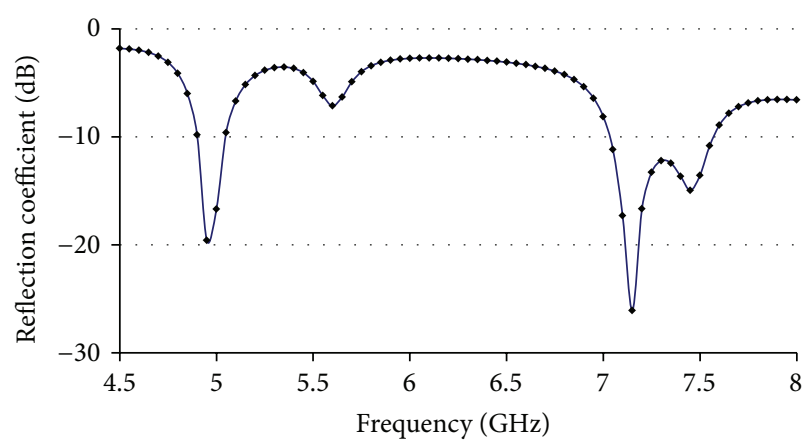

FIGURE 3: Variation of simulated reflection coefficient with frequency for single layer elliptical patch antenna.

This paper uses the following concept: a patch placed close to the fed patch gets excited through the coupling between the patches, and such a patch is known as a parasitic patch. If the resonance frequencies $f_{1}$ and $f_{2}$ of these two patches are placed close to each other, then broad bandwidth is obtained as shown in Figure 1. The overall input VSWR will be the superposition of the responses of the two resonators resulting in a wide bandwidth. If the bandwidth is narrow for the individual patch, then the difference between $f_{1}$ and $f_{2}$ should be small as shown in Figure 1(a). If the bandwidth of the individual patch is large, then the difference in the 


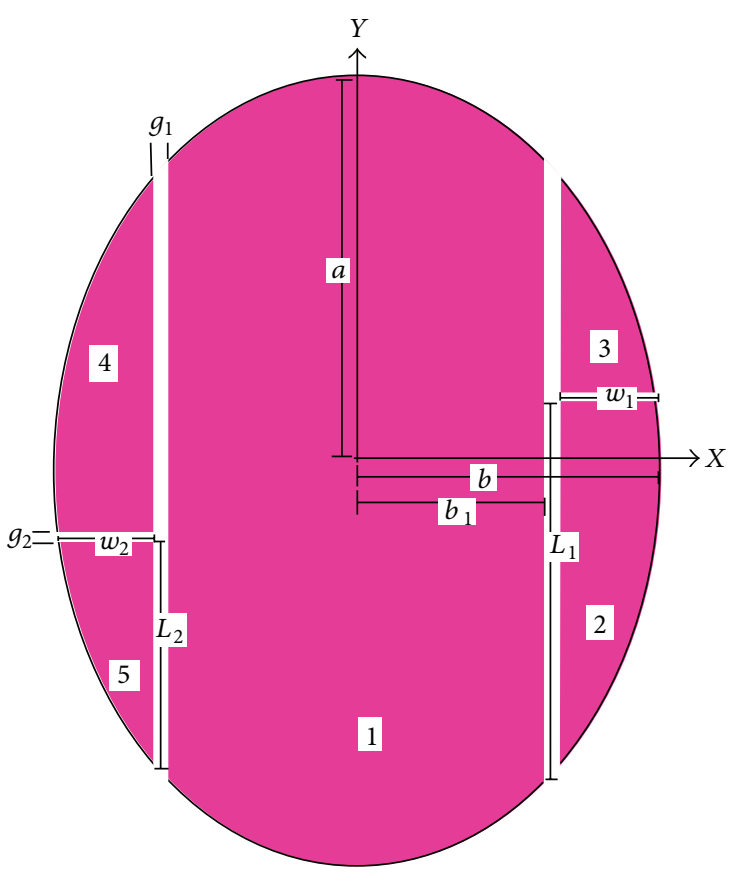

(a)

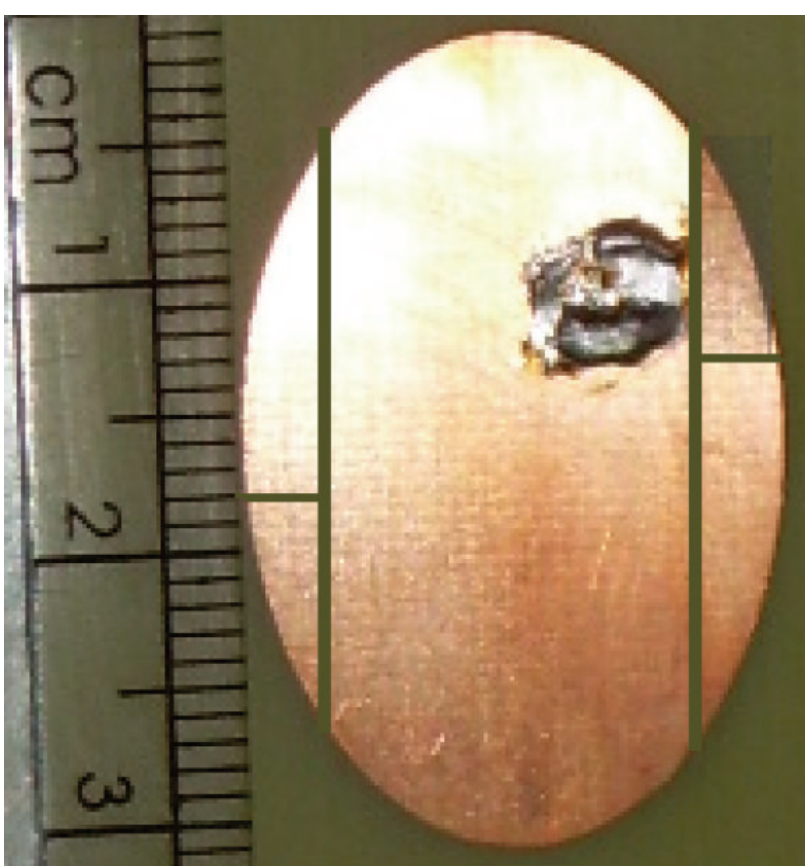

(b)

FIGURE 4: (a) View of assembly of patches forming gap coupled elliptical patch antenna. (b) Photograph of designed antenna.

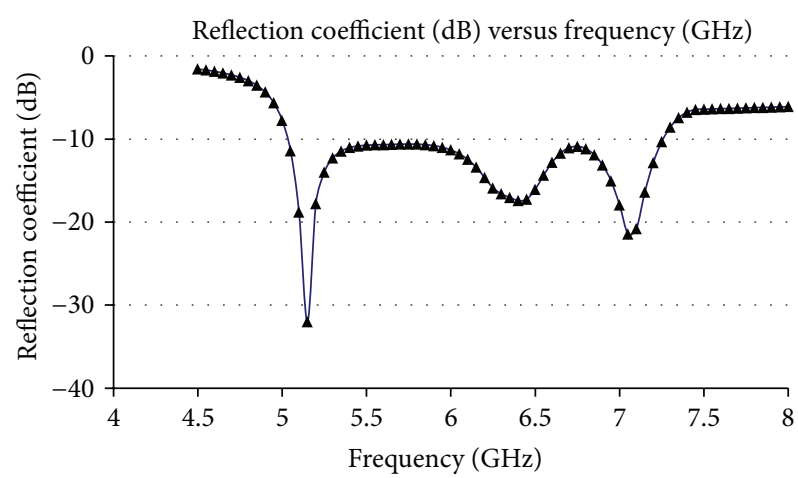

FIGURE 5: Simulated reflection coefficient for an assembly of patches forming gap coupled elliptical patch antenna.

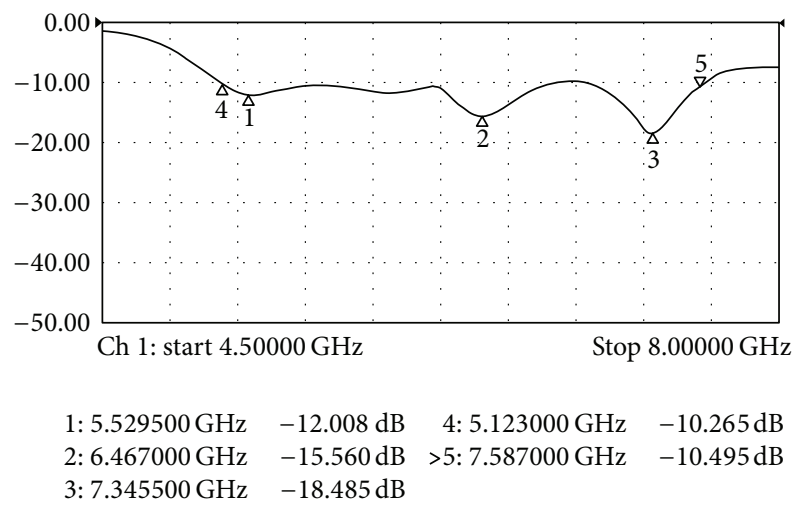

FIGURE 6: Measured reflection coefficient for an assembly of patches forming gap coupled elliptical patch antenna.

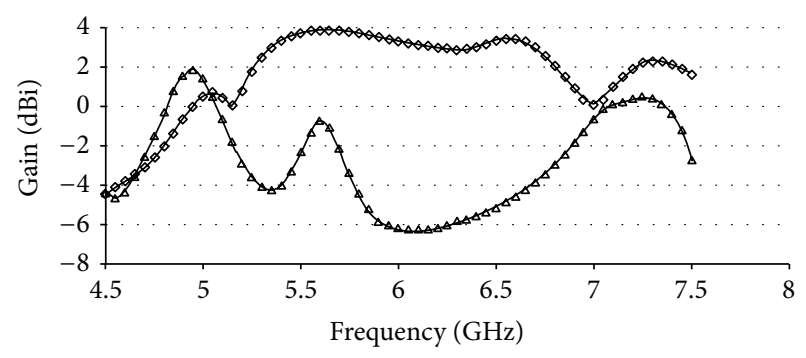

$\diamond$ Modified elliptical patch microstrip antenna

$\triangle$ Conventional elliptical patch microstrip antenna

FIgURE 7: Comparison of simulated maximum total field gain of the gap coupled elliptical patch antenna to conventional elliptical patch antenna.

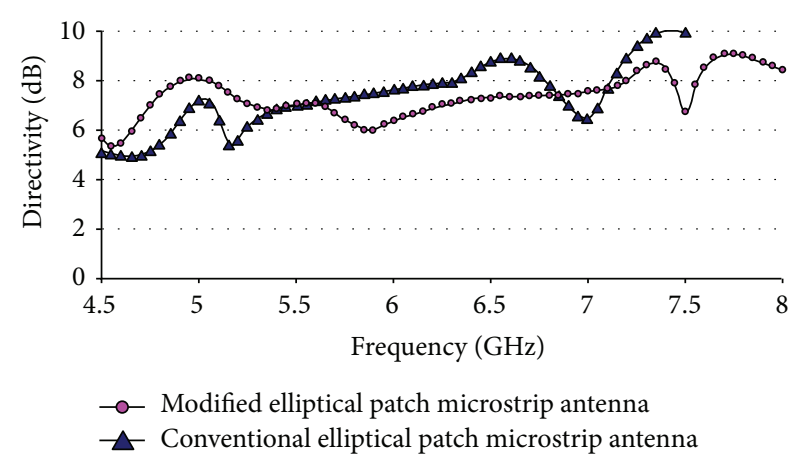

FIGURE 8: Comparison of simulated total field directivity of the gap coupled elliptical patch antenna to conventional elliptical patch antenna. 


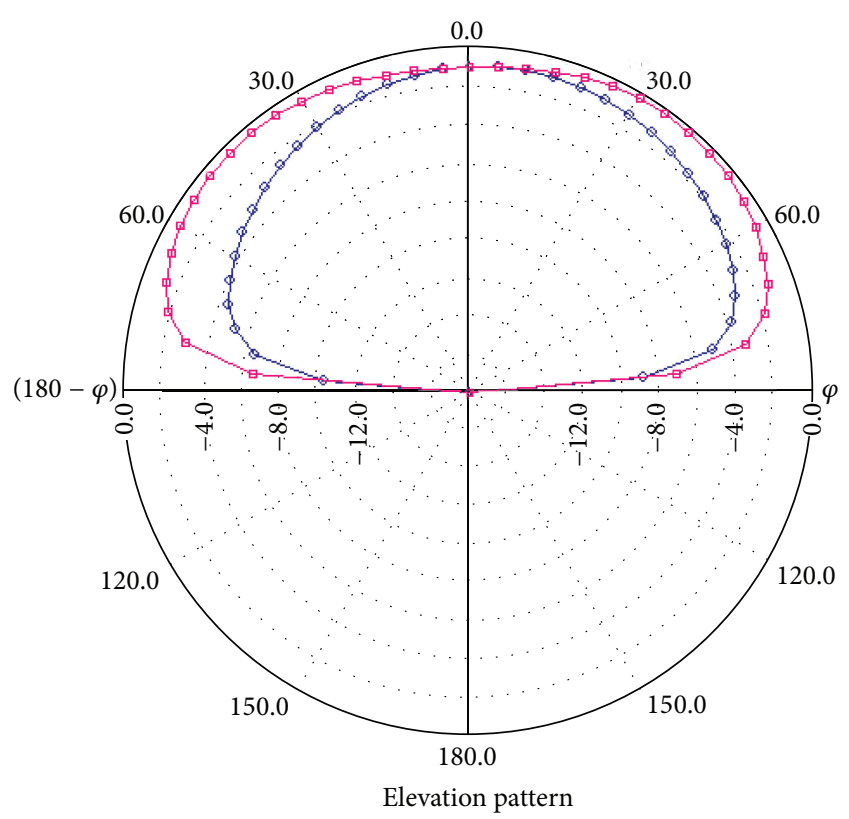

$\diamond f=5.15(\mathrm{GHz}), E$-total, phi $=0(\mathrm{deg})$

$\square \quad f=5.15(\mathrm{GHz}), E$-total, phi $=90(\mathrm{deg})$

FIGURE 9: Simulated elevation pattern at the frequency $5.15 \mathrm{GHz}$.

two frequencies should be large to yield an overall wide bandwidth as shown in Figure 1(b).

\section{Antenna Design and Results}

2.1. Single Layer Elliptical Microstrip Antenna (Conventional). In first step of proposed work, the performance of a conventional elliptical patch microstrip patch antenna having semimajor and semiminor axes dimensions " $a$ " $=15 \mathrm{~mm}$ and $" b "=10 \mathrm{~mm}$, respectively, is simulated by applying method of moments based IE3D simulation software [22]. This antenna is designed and fabricated on glass epoxy FR-4 substrate having metallic copper ground plane with substrate relative permittivity $\varepsilon_{r}=4.4$, substrate thickness $h=1.59 \mathrm{~mm}$, and loss tangent $\tan \delta=0.025$ and is later tested using vector network analyzer [23]. The antenna is fed with single inset feed arrangement through SMA connector. The feed arrangement and the designed antenna are shown in Figures 2 (a) and 2(b), respectively.

Through simulation analysis of this antenna, it is realized that in the frequency range $4.5 \mathrm{GHz}$ to $8.0 \mathrm{GHz}$ antenna resonates at four frequencies $4.95 \mathrm{GHz}, 5.6 \mathrm{GHz}, 7.15 \mathrm{GHz}$, and $7.45 \mathrm{GHz}$, respectively, as shown in Figure 3, which corresponds to different modes of excitation. The impedance bandwidths of this antenna at all the frequencies are very narrow except at frequency $7.15 \mathrm{GHz}$ where it is about $6.7 \%$. The gain and efficiency of antenna are also low; hence, elliptical patch antenna in its present form is not much suitable for modern communication systems. It requires some modification before being used in any practical application.

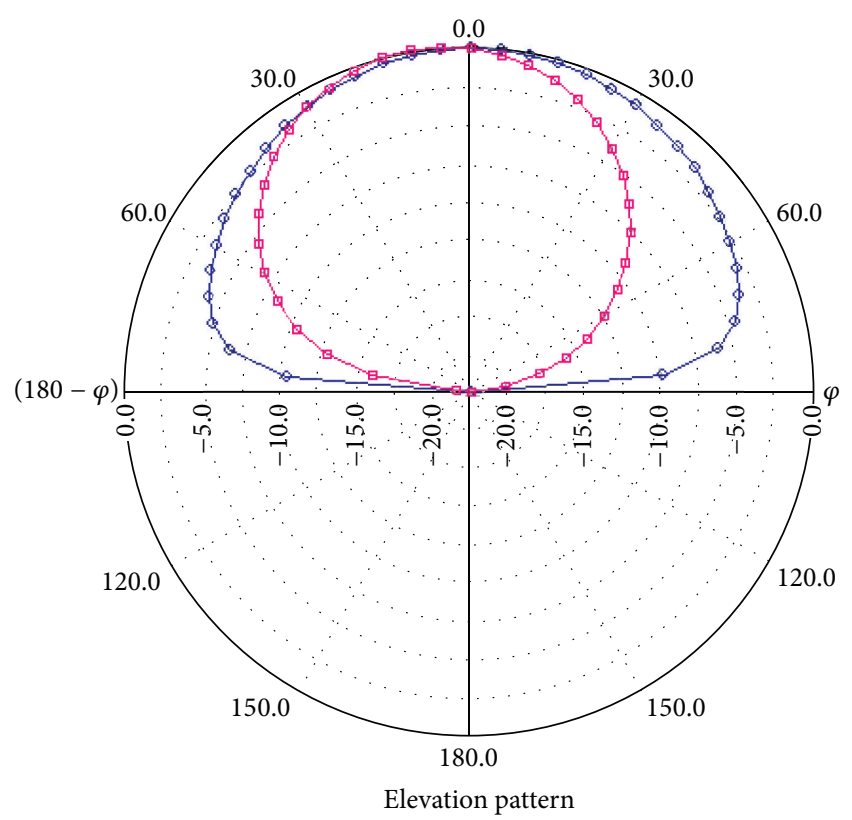

$$
\begin{aligned}
& \diamond \quad f=6(\mathrm{GHz}), E \text {-total, phi }=0(\mathrm{deg}) \\
& \square \quad f=6(\mathrm{GHz}), E \text {-total, phi }=90(\mathrm{deg})
\end{aligned}
$$

Figure 10: Simulated elevation pattern at the frequency $6.00 \mathrm{GHz}$.

In the next section, this conventional elliptical patch is modified.

2.2. Single Layer Gap Coupled Elliptical Microstrip Antenna. In this section, conventional elliptical patch antenna is modified to attain better-quality broadband performance as the conventional elliptical patch antenna, which resonates at four frequencies but presents narrow bandwidth.

The layout of single layer assembly of gap coupled elements in elliptical shape is shown in Figure 4. It represents that among the five patches considered in the present assembly, the two pairs of patches (patch 2 and patch 4) having different patch areas in association with patch 3 and patch 5 and are arranged around an edge truncated elliptical patch to attain higher impedance bandwidth. The central edge truncated elliptical patch is fed through inset feed arrangement and the other patches are parasitically gap coupled to the central patch. Extensive optimizations in width and position of slot along major and minor axes of conventional elliptical patch antenna are carried out to achieve best performance from this assembly of patches. The design parameters of different patches are listed in Table 1.

Figure 4 depicts that, in modified structure, an elliptical patch is alienated as an arrangement of five different patches coupled together parasitically. The overall dimension of the assembly of patches is the same as that reported in previous case for a conventional elliptical patch antenna. In first step, after optimization, two vertical slots of width $g_{1}=0.7 \mathrm{~mm}$ are introduced and afterward two outer gap coupled parts are further divided by two additional horizontal slots of width $g_{2}=0.5 \mathrm{~mm}$ to achieve the best performance from this 
TABLE 1: Design parameters for the proposed gap coupled elliptical microstrip patch antenna.

\begin{tabular}{|c|c|c|}
\hline Serial number & Design parameter & Values \\
\hline \multirow{3}{*}{1} & Dimensions of elliptical patch: & \\
\hline & (i) semimajor axis & “ $a "=1.5 \mathrm{~cm}$ \\
\hline & (ii) semiminor axis & $" b "=1.0 \mathrm{~cm}$ \\
\hline \multirow{3}{*}{2} & Central edge truncated ellipse (1) & \\
\hline & (i) length of semimajor axis & $" a=a_{1} "=1.5 \mathrm{~cm}$ \\
\hline & (ii) length of semiminor axis after truncation & $" b_{1} "=0.57 \mathrm{~cm}$ \\
\hline 3 & Dimensions of patches (2) and (4) & $" L_{1} "=1.33 \mathrm{~cm}, " W_{1} "=0.35 \mathrm{~cm}$ \\
\hline 4 & Dimensions of patches (3) and (5) & $" L_{2} "=0.94 \mathrm{~cm}, " W_{2} "=0.35 \mathrm{~cm}$ \\
\hline 5 & Width of gaps & $" g_{1} "=0.7 \mathrm{~mm}, " g_{2} "=0.5 \mathrm{~mm}$ \\
\hline
\end{tabular}

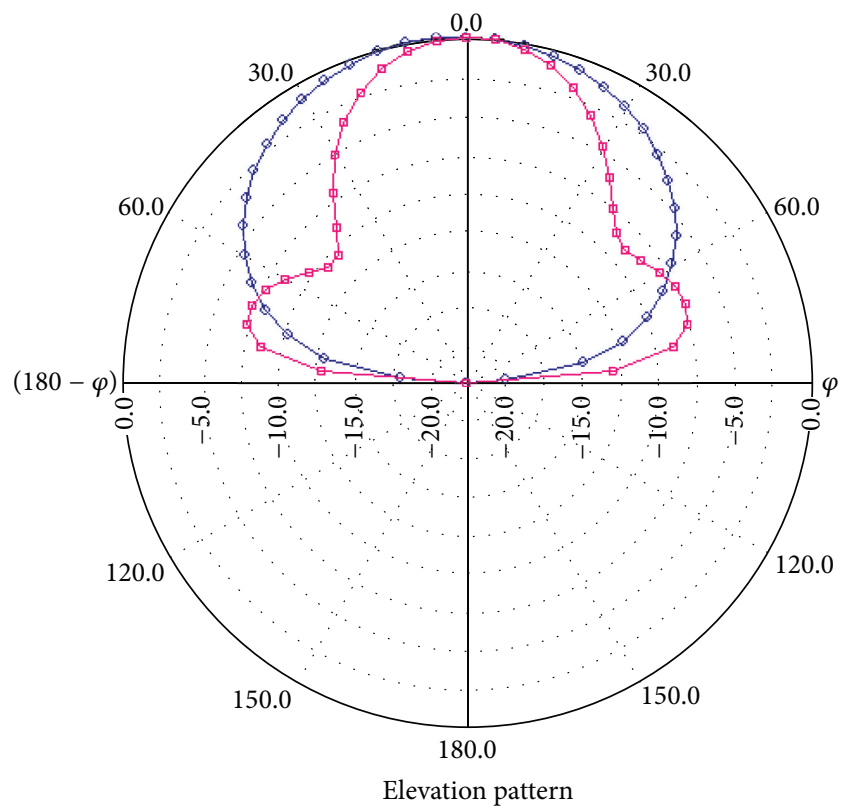

$\diamond f=7.25(\mathrm{GHz}), E$-total, $\mathrm{phi}=0(\mathrm{deg})$

FIGURE 11: Simulated elevation pattern at the frequency 7.25 GHz.

assembly. Inset feed arrangement through SMA connector in association with $50 \mathrm{ohm}$ feed line is applied to feed the central radiating patch (patch 1 ). The gap spacing between gap coupled patches along the vertical direction is taken slightly different from gap spacing between gap coupled patches along horizontal direction in order to excite some additional resonant mode. If the resonance frequencies of these gap coupled patches are close to each other, then larger bandwidth may be obtained as shown in Figure 5.

The simulated and measured reflection coefficient results of assembly of patches forming gap coupled elliptical patch antenna as a function of frequency are shown in Figures 5 and 6 , respectively. The simulated results of antenna present three clear resonances at frequencies $5.17 \mathrm{GHz}, 6.40 \mathrm{GHz}$, and $7.12 \mathrm{GHz}$, respectively, while the measured resonance frequencies are $5.25 \mathrm{GHz}, 6.46 \mathrm{GHz}$, and $7.35 \mathrm{GHz}$, respectively. The simulated impedance bandwidth of antenna is $2.25 \mathrm{GHz}$ while the measured impedance bandwidth is nearly $2.45 \mathrm{GHz}$ (or 36.2\%), which indicates close agreement between simulated and measured resonance frequencies and impedance bandwidths.

Figure 7 shows the comparison of simulated maximum total field gain of the gap coupled elliptical patch antenna to conventional elliptical patch antenna. It indicates that the gain of conventional single layer patch antennas is very poor whereas for proposed gap coupled elliptical patch antenna the gain of antenna is around $4.0 \mathrm{dBi}$ and variation in gain with frequency is within $1.6 \mathrm{dBi}$ within the frequency spectrum of interest. These gain values are improved more than those which were realized with conventional elliptical patch antenna. Figure 8 depicts the comparison of simulated total field directivity of the gap coupled elliptical patch antenna to conventional elliptical patch antenna which indicates that for gap coupled elliptical patch antenna the directivity is around $8.0 \mathrm{dBi}$ and it is more or less unaffected within the frequency range of interest. The gain and efficiency values of antenna are not remarkable and are found to be low due to application of glass epoxy FR-4 substrate material, which have high dielectric constant (4.4) and loss tangent (0.025) values. By applying air/foam substrate or low loss tangent materials, these parameters may be improved as per the application.

The simulated $\mathrm{E}$ and $\mathrm{H}$ plane far field elevation patterns of proposed assembly of patches forming gap coupled elliptical patch antenna at the three resonance frequencies $5.15 \mathrm{GHz}$, 6.0 GHz, and 7.25 GHz are shown in Figures 9, 10, and 11. At all the three frequencies, the direction of maximum radiations is normal to patch geometry and patterns are systematical in nature. At all the three frequencies a null near to the broadside $(\theta=0)$ is observed. These patterns suggest that the direction of maximum radiations is normal to patch geometry and patterns are symmetrical in nature in entire frequency range of interest.

\section{Conclusions}

A new design of broadband single layer assembly of patches forming gap coupled elliptical patch antenna is presented in this communication. By properly choosing the suitable slot dimension of gap coupling, at proper location and adjusting their dimensions, a wide operating bandwidth with relatively small size and improved radiation pattern is obtained. More 
wide impedance bandwidth at lower frequencies can also be realized by properly upscaling and modifying the relative parameters of proposed antenna. The radiation patterns throughout in the impedance bandwidth are identical in shape and direction of maximum intensity is directed normally to patch geometry. Measured results display exemplary accuracy with simulated results thereby justifying the use of such techniques for synthesis of single element antenna.

\section{Conflict of Interests}

The author declares that there is no conflict of interests regarding the publication of this paper.

\section{Acknowledgment}

The author expresses his sincere thanks to Professor Deepak Bhatnagar, University of Rajasthan, Jaipur, for his expert comments on the paper and help in carrying out the measurements on VNA (vector network analyzer).

\section{References}

[1] G. Kumar and K. P. Ray, Broadband Microstrip Antennas, Artech House, London, UK, 2003.

[2] K. L. Wong, Compact and Broadband Microstrip Antennas, John Wiley \& Sons, New York, NY, USA, 2003.

[3] C. K. Wu and K. L. Wong, "Broadband microstrip antenna with directly coupled and gap coupled parasitic patches," Microwave and Optical Technology Letters, vol. 22, pp. 348-349, 1999.

[4] V. Sharma, V. K. Saxena, J. S. Saini et al., "Wideband dualfrequency right triangular microstrip antenna with parallel narrow slits," Microwave and Optical Technology Letters, vol. 52, no. 5, pp. 1082-1087, 2010.

[5] D. M. Pozar and D. H. Schaubert, Microstrip Antennas, IEEE Press, New York, NY, USA, 1995.

[6] V. Sharma, S. Shekhawat, V. K. Saxena et al., "Right isosceles triangular microstrip antenna with narrow l-shaped slot," Microwave and Optical Technology Letters, vol. 51, no. 12, pp. 3006-3010, 2009.

[7] F. Yang, X. Zhang, X. Ye, and Y. Rahmat-Samii, "Wide-band E-shaped patch antennas for wireless communications," IEEE Transactions on Antennas and Propagation, vol. 49, no. 7, pp. 1094-1100, 2001.

[8] A. A. Abdelaziz, "Bandwidth enhancement of microstrip antenna," Progress in Electromagnetics Research, vol. 63, pp. 311317, 2006.

[9] X. L. Bao and M. J. Ammann, "Small patch/slot antenna with 53\% input impedance bandwidth," Electronics Letters, vol. 43, no. 3, pp. 146-148, 2007.

[10] V. Sharma and M. M. Sharma, "Wideband gap coupled assembly of rectangular microstrip patches for Wi-Max applications," Frequenz, vol. 68, pp. 25-31, 2013.

[11] A. Singh, J. A. Ansari, Kamakshi, M. Aneesh, and S. S. Sayeed, "L-strip proximity fed gap coupled compact semi-circular disk patch antenna," Alexandria Engineering Journal, vol. 53, no. 1, pp. 61-67, 2014.

[12] P. Kumar and G. Singh, "Gap-coupling: a potential method for enhancing the bandwidth of microstrip antennas," Advanced
Computational Techniques in Electromagnetics, vol. 2012, Article ID acte-00110, 6 pages, 2012.

[13] C. Wood, "Improved bandwidth of microstrip antennas using parasitic elements," IEE Proceedings H: Microwaves, Optics and Antennas, vol. 127, no. 4, pp. 231-234, 1980.

[14] G. Kumar and K. C. Gupta, "Broadband microstrip antennas using additional resonators gap-coupled to the radiating edges," IEEE Transactions on Antennas and Propagation, vol. 32, no. 12, pp. 1375-1379, 1984.

[15] V. Sharma, V. K. Saxena, J. S. Saini, D. Bhatnagar, K. B. Sharma, and L. M. Joshi, "Broadband gap-coupled assembly of patches forming elliptical patch antenna," Microwave and Optical Technology Letters, vol. 53, no. 2, pp. 340-344, 2011.

[16] K. P. Ray, V. Sevani, and R. K. Kulkarni, "Gap coupled rectangular microstrip antennas for dual and triple frequency operation," Microwave and Optical Technology Letters, vol. 49, no. 6, pp. 1480-1486, 2007.

[17] N. Kumprasert and W. Kiranon, "Simple and accurate formula for the resonant frequency of the circular microstrip disk antenna," IEEE Transactions on Antennas and Propagation, vol. 43, no. 11, pp. 1331-1333, 1995.

[18] J. G. Kretzschmar, "Wave propagation in hollow conducting elliptical waveguides," IEEE Transactions on Microwave Theory and Techniques, vol. 18, no. 9, pp. 547-554, 1970.

[19] C. Y. Huang and W. C. Hsia, "Planar elliptical antenna for ultrawideband communications," Electronics Letters, vol. 41, no. 6, pp. 296-297, 2005.

[20] H. Jung and C. Seo, "Analysis of elliptical microstrip patch antenna considering attachment mode," IEEE Transactions on Antennas and Propagation, vol. 50, no. 6, pp. 888-890, 2002.

[21] D. Bhardwaj, K. Sharma, D. Bhatnagar, S. Sancheti, and B. Soni, "Design and analysis of a gap coupled split circular patch with elliptical slot filled with elliptical patch," Indian Journal of Radio and Space Physics, vol. 39, no. 2, pp. 107-113, 2010.

[22] IE3D Software, Release 8, Zeland Software, Freemont, Calif, USA.

[23] E8363C PNA Series Microwave Network Analyzer, $10 \mathrm{MHz}$ to $40 \mathrm{GHz}$. 

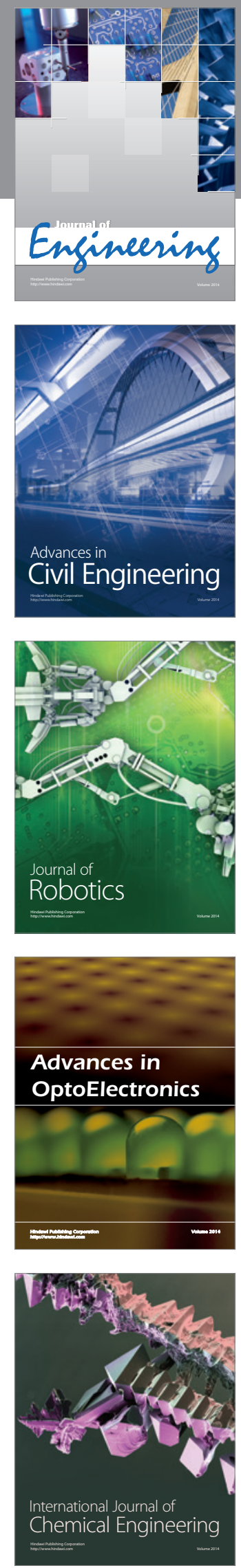

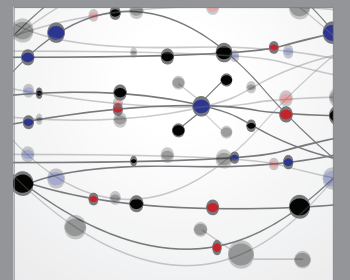

The Scientific World Journal
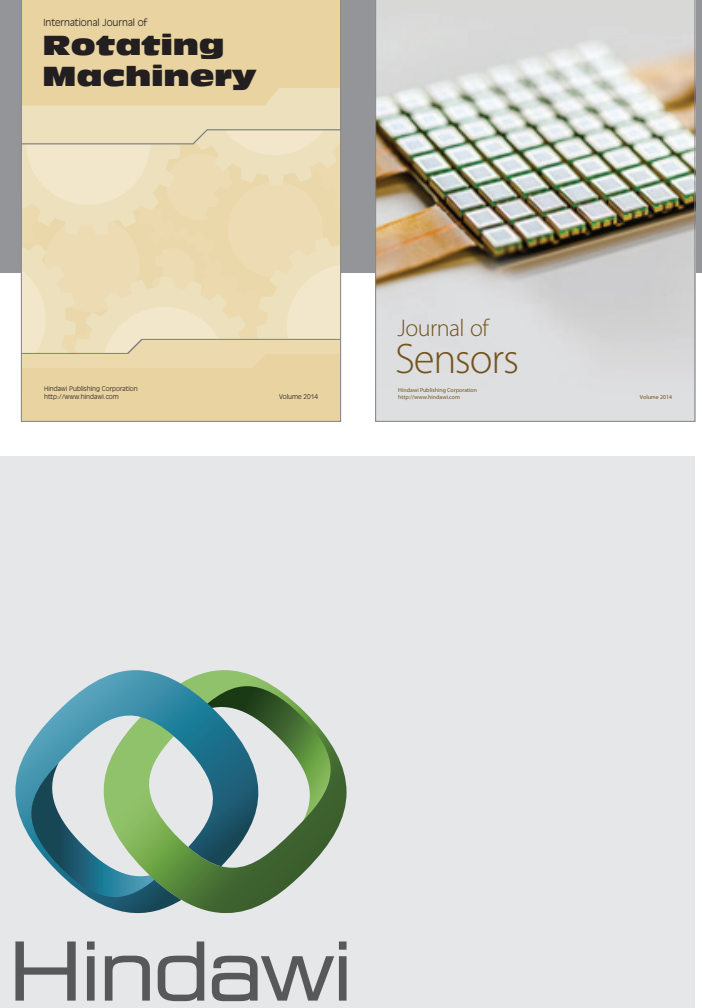

Submit your manuscripts at http://www.hindawi.com
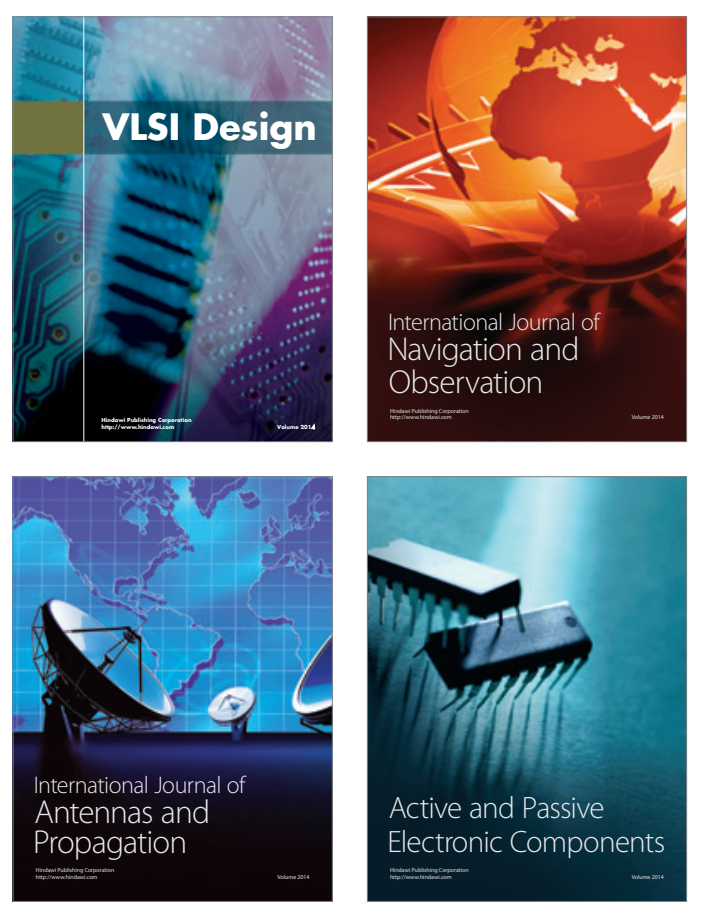
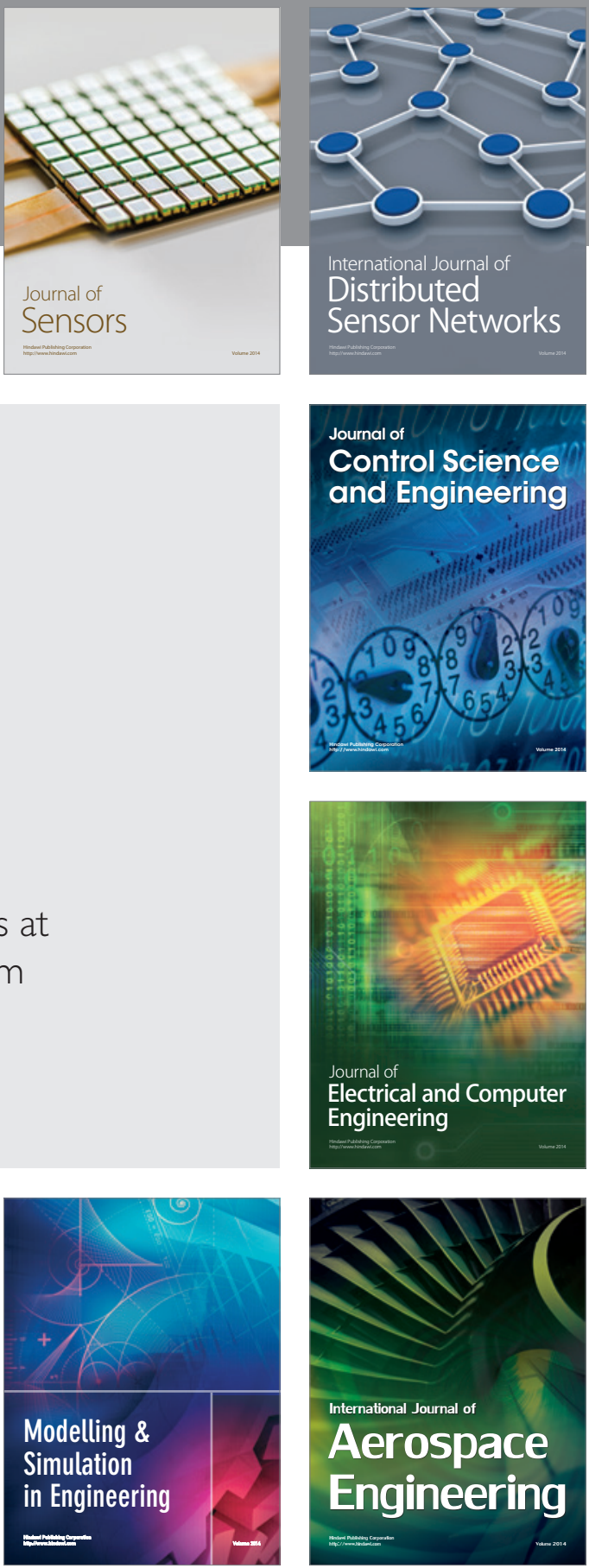

Journal of

Control Science

and Engineering
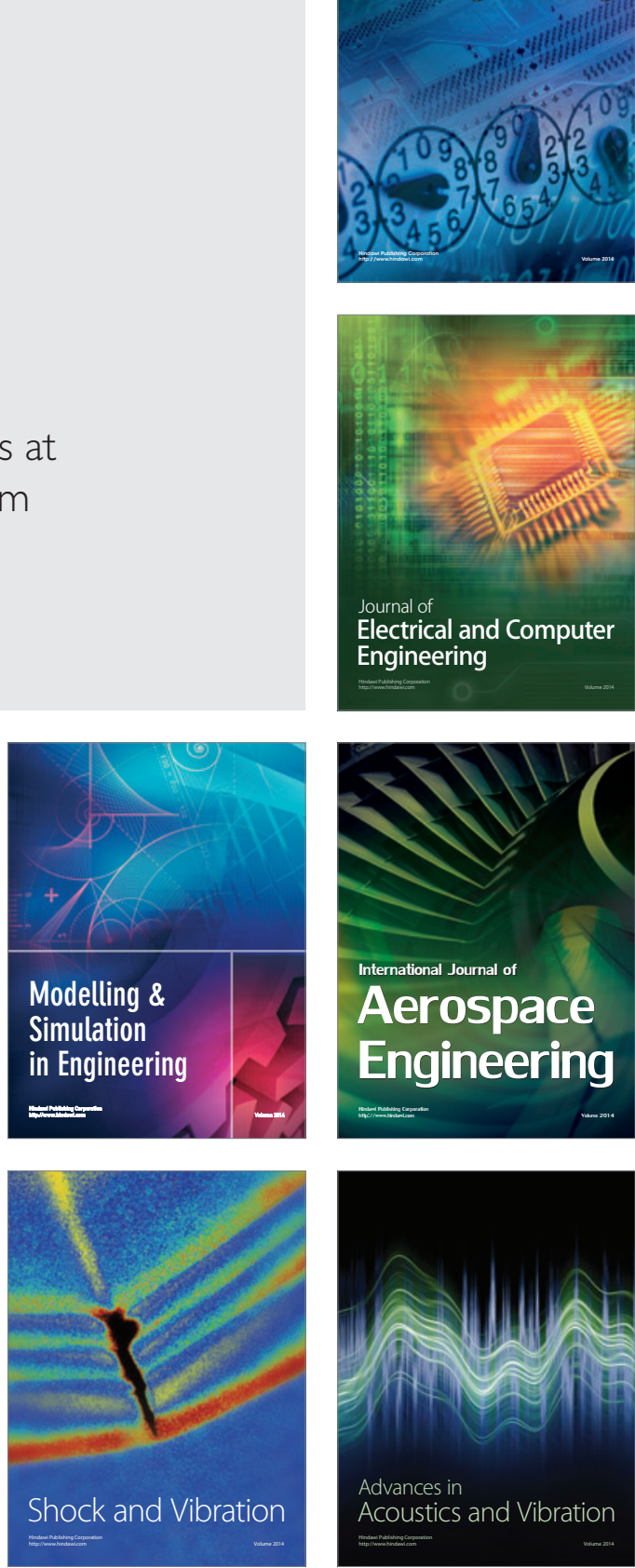